\title{
Amphibian sex determination: segregation and linkage analysis using members of the tiger salamander species complex (Ambystoma mexicanum and $A$. t. tigrinum)
}

\author{
JJ Smith ${ }^{1,2,3}$ and SR Voss ${ }^{1}$ \\ ${ }^{1}$ Department of Biology and Spinal Cord, Brian Injury Research Center, University of Kentucky, Lexington, KY, USA; ${ }^{2}$ Department of \\ Genome Sciences, University of Washington, Seattle, WA, USA and ${ }^{3}$ Benaroya Research Institute at Virginia Mason, Seattle, WA, USA
}

\begin{abstract}
Little is known about the genetic basis of sex determination in vertebrates though considerable progress has been made in recent years. In this study, segregation analysis and linkage mapping were performed to localize an amphibian sexdetermining locus (ambysex) in the tiger salamander (Ambystoma) genome. Segregation of sex phenotypes (male and female) among the second generation individuals of interspecific crosses (Ambystoma mexicanum $\times$ Ambystoma tigrinum tigrinum) was consistent with Mendelian expectations, although a slight female bias was observed. Individuals from these same crosses were typed for singlenucleotide polymorphisms distributed throughout the genome to identify molecular markers for ambysex. A marker
\end{abstract}

(E24C3) was identified approximately $5.9 \mathrm{cM}$ from ambysex. Linkage of E24C3 to ambysex was independently validated in a second, intraspecific cross ( $A$. mexicanum). Interestingly, ambysex locates to the tip of one of the larger linkage groups of the Ambystoma meiotic map. Considering that this location does not show reduced recombination, we speculate that the ambysex locus may have arisen quite recently, within the last few million years. Localization of ambysex sets the stage for gene identification and provides important tools for studying the effect of sex in laboratory and natural populations of this model amphibian system.

Heredity (2009) 102, 542-548; doi:10.1038/hdy.2009.15; published online 4 March 2009

Keywords: Ambystoma; sex chromosome; sex determination; evolution; linkage map

\section{Introduction}

Distinct sexual phenotypes (for example, male and female) are one of the most widespread forms of segregating phenotypic variation among vertebrates, and possibly all eukaryotes. Although mechanisms underlying vertebrate sex determination remain largely unknown, the available evidence suggests incredible diversity among and within each of the major groups. Sex determination in fishes ranges from Mendelian to polygenic, but in some cases, sex is entirely determined by environmental factors (Baroiller et al., 1999; Delvin and Nagahama, 2002; Mank et al., 2006). Environmental sex determination and sex chromosomes are distributed throughout reptilian phylogeny, suggesting independent evolutionary losses and gains, but conserved mechanisms are known for crocodilians (temperature) and birds (chromosomal sex determination; Olmo, 1990; Ewert and Nelson, 1991; Pieau et al., 1999; Shine, 1999; Nanda et al., 2000; Nanda and Schmid, 2002). Of all the major vertebrate groups, sex determination is perhaps the most

Correspondence: Dr JJ Smith, Department of Genome Sciences, Benaroya Research Institute at Virginia Mason, 1201 9th Avenue, Seattle, WA 98101, USA.

E-mail:smithjj@u.washington.edu

Received 30 June 2008; revised 10 December 2008; accepted 22 January 2009; published online 4 March 2009 conserved among placental mammals; however, even within this group, there are a few interesting exceptions to the SRY gene rule (Sinclair et al., 1990; Just et al., 1995; Soullier et al., 1998; Pask and Graves, 1999). Given the amazing diversity in sex-determining mechanisms that are observed among vertebrates, it is expected that studies of additional groups will not only reveal new diversity, but also will elucidate conservative aspects of sex-determining and sex-differentiating pathways that characterized the ancestral vertebrate condition.

The vast majority of, if not all, amphibian species are thought to exhibit genetic modes of sex determination; however, several evolutionary transitions between $\mathrm{ZW}$ and $X Y$ type sex-determining mechanisms (heterogametic females or males, respectively) may have occurred (Hillis and Green, 1990; Schmid et al., 1991; Hayes, 1998; Wallace et al., 1999; Ogata et al., 2003; Ezaz et al., 2006). Under chromosomal sex determination, sexual differentiation depends upon the inheritance of a homologous $(Z Z$ or $X X)$ or heterologous ( $Z W$ or $X Y$ ) pair of sex chromosomes. Alternate modes of sexual differentiation are determined by the presence or absence of one or more loci between sex chromosomes, or by gene dosage. In either case, alternate sexual phenotypes (male and female) are expected to segregate as simple Mendelian traits, with a resulting 1:1 sex ratio among siblings of a large cross. Although results consistent with a simple Mendelian mode of inheritance have been observed in 
the few amphibian species examined to date, nonMendelian segregation of sexual phenotypes has also been observed (Rana and Hyla spp.: Richards and Nace, 1978; Pleurodeles waltl: Collenot et al., 1994). These studies suggest that sex determination in some amphibians may depend upon more than a single, segregating genetic factor.

Salamanders of the genus Ambystoma are important amphibian models for studying development, ecology and evolution, and with the recent development of a complete genetic map for Ambystoma the prospects of understanding the genetic basis of biologically important trait variation has become a reality (Voss and Smith, 2005). A number of developmental and cytogenetic experiments have established that sex is specified by a ZW-type mechanism of chromosomal sex determination in Ambystoma mexicanum (Humphrey, 1945, 1957; Lindsley et al., 1956; Brunst and Hauschka, 1963; Armstrong, 1984; Cuny and Malacinski, 1985) and possibly Ambystoma tigrinum tigrinum (Cuny and Malacinski, 1985) and members of the Ambystoma jeffersonianum species complex (Sessions, 1982). In addition, sex ratios suggest a single gene basis for sex determination in the laboratory strain of A. mexicanum (Humphrey, 1945, 1957; Lindsley et al., 1956; Armstrong, 1984). However, this hypothesis has not been tested with molecular markers, and no sex determining genes have been mapped.

In this study, we revaluate the hypothesis that sex segregates in a 1:1 ratio when crossing tiger salamander species complex members (sensu Shaffer, 1984). We report segregation ratios of males and females that are largely consistent with the presence of a single sexdetermining factor in the previously described WILD2 (Voss and Smith, 2005) backcross mapping family (wild collected $A$. mexicanum $/ A$. $t$. tigrinum $\times$ wild-collected A. mexicanum) as well as a new 'wild' $A$. mexicanum $\times$ 'lab' A. mexicanum F2 intercross (MEX1). To localize the major sex-determining factor to the Ambystoma genetic map, the WILD2 cross was genotyped for 156 previously developed markers (Smith et al., 2005). The analysis identified a single nucleotide polymorphism (E24C3, linkage group 5) with alleles that associated with male and female phenotypes. Two additional molecular markers were then developed to track segregation of E24C3 alleles within the MEX1 cross. As was observed for the WILD2 cross, segregating genotypes for E24C3 were strongly associated with segregating sex phenotypes in MEX1. Although we note a slight female bias in some crosses, our results validate the existence of a single Mendelian locus (ambysex) that acts as a primary sex-determining factor in A. mexicanum. We also note that patterns of recombination between the mapping panels suggest little differentiation of $Z$ and $W$ sex chromosomes, thus implying a recent origin for this sex determining system.

\section{Materials and methods}

\section{Genetic strains and crosses}

Two crosses were used in this study: WILD2 and MEX1. The cross WILD2 was generated by backcrossing female F1 hybrids between $A$. mexicanum and $A$. $t$. tigrinum to male $A$. mexicanum to generate nine closely related families (Table 1). See Voss and Smith (2005) for a
Table 1 Segregation of sex among backcross progeny and corresponding $G$-tests for goodness of fit to a 1:1 sex ratio

\begin{tabular}{lrcclrrr}
\hline Cross & Male & Female & $\begin{array}{c}\text { Proportion } \\
\text { Female }\end{array}$ & $\begin{array}{l}\text { Test } \\
(\mathrm{G})\end{array}$ & $d f$ & $\mathrm{G}$ & $\mathrm{P}$ \\
\hline 1 & 19 & 41 & 0.68 & & 1 & 8.26 & 0.004 \\
2 & 17 & 23 & 0.58 & & 1 & 0.90 & 0.342 \\
3 & 18 & 13 & 0.42 & & 1 & 0.81 & 0.368 \\
4 & 21 & 24 & 0.53 & & 1 & 0.20 & 0.655 \\
5 & 22 & 23 & 0.51 & & 1 & 0.02 & 0.881 \\
6 & 26 & 36 & 0.58 & & 1 & 1.62 & 0.203 \\
7 & 16 & 20 & 0.56 & & 1 & 0.45 & 0.505 \\
8 & 13 & 13 & 0.50 & & 1 & 0.00 & 1.000 \\
9 & 5 & 10 & 0.67 & & 1 & 1.70 & 0.192 \\
Total & 157 & 203 & 0.56 & Total & 9 & 13.96 & 0.124 \\
& & & & Pooled & 1 & 5.89 & 0.015 \\
& & & & Heterogeneity & 8 & 8.06 & 0.427 \\
\hline
\end{tabular}

Abbreviation: df, degrees of freedom.

detailed description of the crossing design and rearing conditions that were used to generate WILD2. Two strains of $A$. mexicanum were used to generate the MEX1 cross. A female from the laboratory strain of A. mexicanum that is maintained by the Ambystoma Genetic Stock Center (http://www.ambystoma.org/ AGSC/) was crossed to a strain that was more recently derived from the single natural population of $A$. mexicanum that occurs in Lake Xochimilco (Mexico DF, Mexico). Two of the resulting F1 offspring were then mated to generate the MEX1 cross.

\section{Rearing conditions}

At approximately 20 days postfertilization, larvae were released from their eggs and placed individually in 5-oz paper cups of $20 \%$ Holtfretter's solution (Asashima et al., 1989). Throughout the course of these experiments, all individuals from each of the mapping panels were maintained in a single room within which the temperature fluctuated from 19 to $22{ }^{\circ} \mathrm{C}$. Individuals were reared in separate containers and rotated within the room after water changes to reduce the effects of spatial temperature variation. Larvae were fed freshly hatched Artemia twice daily for their first 30 days posthatching. After day 20 , their diet was supplemented with small $(<1 \mathrm{~cm}$ long) California black worms (Lumbriculus). During this time, individuals were provided with fresh water and cups after every third feeding. On day 30, larvae were transferred to 16-oz plastic bowls, after which they were fed exclusively California black worms, and water was changed every third day. Finally, at 80 days postfertilization, all individuals were transferred to 4-1 plastic containers and were otherwise maintained under the same regime as the previous 50 days.

\section{Phenotypic scores}

WILD2: The majority of WILD2 offspring were euthanized upon the completion of metamorphosis or at day 350. At this time, individuals were dissected, tissue samples (liver and/or blood) were harvested for DNA isolation, and gonads were examined to identify each individual's sex phenotype. Individuals with gonads consisting of a membrane surrounding translucent (immature ova) or opaque/pigmented (more mature ova) spheres were classified as females. 
Individuals with gonads appearing as opaque-ovoid (immature testes) or lobed (more mature testes) structures were classified as males. Individuals metamorphosing early in the experiment often could not be unequivocally assigned to either sex (Humphrey, 1929; Gilbert, 1936); these individuals were classified as immatures. Gonads of immatures appeared as a thin strip of tissue (undifferentiated gonadal primordia or early stages of differentiation) adjacent to the abdominal fat bodies. A few individuals were not euthanized and are currently being maintained for use in future studies. For these individuals, sex was scored after the development of secondary sexual characteristics. In particular, the cloacal opening of male ambystomatids is much longer than that of females, and male cloacal lips are several times larger than those of females. Dissected animals invariably corroborated cloacal sex scores. Sex was identified for a total of 360 WILD2 individuals within this study.

MEX1: Sex phenotypes for the MEX1 cross were scored in the same manner as described for the WILD2, except that all animals from this cross were pedomorphic, and all individuals were scored at day 310 postfertilization. At this age, all animals had completed gonadal differentiation, and sex phenotypes were unequivocally identified for all 93 individuals.

\section{Genotyping}

On the basis of earlier studies, which suggested that the sex-determining gene of ambystomatids resides on one of the smaller chromosomes (A. mexicanum and $A$. $t$. tigrinum-Brunst and Hauschka, 1963; A. jeffersonianum species complex-Sessions, 1982; Cuny and Malacinski, 1985), an initial screen for the sex-determining factor was targeted to the five smallest linkage groups, LG10-LG14 (Smith et al., 2005). In this screen, 54-161 individuals of known sex phenotype ( $>195$ days old) were genotyped for 23 molecular markers that were broadly scattered across these linkage groups (Supplementary Tables 1 and 2). A second screen targeted the remaining nine linkage groups of the map. This screen used an initial panel of 24 pedomorphs and late-metamorphosing individuals (12 males and 12 females) from WILD2.3, and targeted 124 previously described genetic markers (Smith et al., 2005) that were spaced at roughly 30-cM intervals (Supplementary Tables 1-3). On the basis of the analyses of genotypes from the initial screens, E24C3 and E26C11 were also genotyped for a larger subset of the WILD2 panel ( $n=375$ for E24C3; $n=74$ for E26C11).

Three novel genetic markers were developed for this study, using previously described methods (Smith et al., 2005). One of these probes (E26C11_329_3.1_A/GGGGTTCTCTCAATGAACTGTATGTTGATTG) was designed to genotype the marker E26C11 in WILD2. Two additional fluorescence polarization probes were developed to genotype the E24C3 marker fragment in the MEX1 cross (E24C3_79_3.1_G/A-CTGTGGTGTATTCG AACATGTCGC, and E24C3_318_3.1_G/A-AGGGCCT TCACATATTTTTCTGCAAAATAT). Polymorphisms segregating in the WILD1 cross were identified by sequencing E24C3 PCR amplicons from the P1 and F2 founders. These markers were genotyped using standard primer extension and fluorescence polarization protocols [AcycloPrime-FP chemistry and Wallac, Victor3 plate reader (PerkinElmer,
Waltham, MA, USA)]; (Chen et al., 1999; Hsu et al., 2001; Gardiner and Jack, 2002).

\section{Statistical analyses: segregation of sex}

Sex ratios within crosses were examined for fit to a 1:1 ratio expected under single locus sex determination, using G-tests (Sokal and Rohlf, 1995). As WILD2 consisted of several crosses, tests for homogeneity $\left(G_{\text {heterogeneity }(\mathrm{h})}\right)$ among crosses and fit to a 1:1 sex ratio in the data pooled across crosses $\left(G_{\text {pooled (p) }}\right)$ were performed in addition to the tests for fit to a 1:1 sex ratio for individual crosses (G; Sokal and Rohlf, 1995). Lack of fit to a 1:1 sex ratio would suggest that genetic factors, in addition to a single locus, might contribute to sex determination in Ambystoma.

\section{Association analyses}

Likelihood ratio statistics (LRS) for association of phenotypic variation with genotypic inheritance were estimated using the interval mapping and marker regression functions of MapManagerQTXb19 (Meer et al., 2004). Significance thresholds for interval mapping were obtained through 10000 permutations of trait values among backcross progeny.

\section{Results}

\section{Segregation of sex}

WILD2: The sex of 360 WILD2 individuals was identified by gonadal and/or cloacal morphology. All remaining larvae $(n=137)$ were scored immature. The ratios of males to females from eight of nine crosses were consistent with a 1:1 ratio expected under the hypothesis that a single locus specifies sex in Ambystoma (Table 1). A significantly female-biased sex ratio was observed in Cross $1(\mathrm{G}=8.26, \mathrm{DF}=1, P=0.004)$, and nonsignificant female bias was observed in five other crosses. Sex ratios among crosses were not significantly heterogenous $\left(G_{h}=8.06, D F=8, P=0.427\right)$; therefore, data for sex were pooled and tested for fit to a 1:1 ratio. Pooling of femalebiased sex ratios among individual crosses revealed an overall female-biased sex ratio (203 females and 157 males) that deviated significantly from the $1: 1$ ratio $\left(\mathrm{G}_{\mathrm{p}}=8.06, \mathrm{DF}=1, P=0.015, n=360\right)$.

MEX1: Sex phenotypes were obtained for a total of 93 individuals from the MEX1 cross (46 males and 47 females). As was observed for the majority of WILD2 crosses, the sex ratio in MEX1 is consistent with a 1:1 ratio expected under the hypothesis that a single locus specifies sex in Ambystoma ( $\mathrm{G}=0.01, \mathrm{DF}=1, P=0.917$, $n=93)$.

\section{Segregation of molecular markers in WILD2}

A total of 159 markers were genotyped for the WILD 2 cross. The distribution of these markers across the linkage map (Smith et al., 2005) indicates that 92\% of map is within $30 \mathrm{cM}$ of at least one the molecular markers, and $73 \%$ of the map is within $15 \mathrm{cM}$. Most of the regions that were not covered by this screen are represented only by anonymous (AFLP) markers. Segregation ratios of molecular markers deviated from a 1:1 ratio less often than expected on the basis of the distribution of values for the $\chi^{2}$-test for 1:1 segregation 
(Supplementary Figure 1). A similar pattern of deviation from $\chi^{2}$-test, toward unity, was observed in an earlier study that mapped the same markers using independently generated crosses (Smith et al., 2005). These results show that the segregation of molecular markers in A. mexicanum $\times A$. $t$. tigrinum interspecific crosses is not distorted.

\section{Linkage analysis of sex in WILD2}

Genetic screens for sex-associated regions of the Ambystoma genome identified a single marker (E24C3) that was completely associated with the segregation of sex phenotypes in the subpopulation of 24 WILD2 offspring that were used for the initial genome scan. This marker is the most terminal gene/EST-based marker at one tip of LG5. The WILD2 mapping family was generated using a backcross mating design; therefore, individuals segregated two genotypes for the E24C3 marker, E24C3 $3^{\mathrm{G} / G}$ (homozygous for the A. mexicanum genotype) and $E 24 C 3^{G / A}$ (A. mexicanum/A. t. tigrinum heterozygotes; Table 2 ). The male phenotype was associated with the inheritance of the heterozygous $E 24 C 3^{G / A}$ genotypes, whereas the female phenotype was associated with the inheritance of the homozygous $E 24 C 3^{G / G}$ genotype. The pattern of segregation of $E 24 C 3^{G / G}$ vs $E 24 C 3^{G / A}$ genotypes is consistent with the previously shown ZW (heterogametic female) sex-determining mechanism of $A$. mexicanum (Humphrey, 1945, 1957; Lindsley et al., 1956; Armstrong, 1984), given that the P1 A. mexicanum and the F1 hybrid were females ( $\mathrm{Z}^{\text {A.mexicanum (A.mex) }} / \mathrm{W}^{\text {A.mex }}$ and $\mathrm{Z}^{\text {A.t.tigrinum (A.t.t) }} / \mathrm{W}^{\text {A.mex }}$, respectively) and the P1 A.t.tigrinum and P2 A. mexicanum were males ( $Z^{\text {A.t.t }} / Z^{\text {A.t.t }}$ and $Z^{\text {A.mex }} / Z^{\text {A.mex }}$, respectively). Backcross progeny can therefore only inherit two genotypes $\left(Z^{A . m e x} /\right.$ $Z^{\text {A.t.t. }}$ male) or $\left(\mathrm{Z}^{\text {A.mex }} / \mathrm{W}^{\text {A.mex }}\right.$ : female). According to this model, second generation females inherited a $W^{A . m e x}$ locus, and frequently a linked $E 24 C 3^{G}$ (A. mexicanum) allele from their F1 mother.

To further resolve the position of the sex-associated region on LG5, larger panels of late-metamorphosing individuals (at least 175 days old at metamorphosis) were genotyped for the E24C3 marker $(n=221)$ and the flanking marker, E26C11 $(n=74)$. Again, segregating genotypes for these markers were strongly associated with the segregation of sexes (E24C3: LRS $=220, P<1 \mathrm{E}-5$; E26C11: $\mathrm{LRS}=13.8, P=2 \mathrm{E}-4$; Tables 2 and 3). On the basis of these genotypes, the most likely position for a single sex determining locus is $10.6 \mathrm{cM}$ distal to the position of E24C3 on LG5 (Figure 1).

With sex locus markers in hand, we determined E24C3 genotypes for the 154 early metamorphosing individuals ( $<175$ days old at metamorphosis), who either possessed morphologically undifferentiated gonads or were in early stages of morphological differentiation. Among these animals, there were $79 E 24 C 3^{G / G}$ homozygotes (presumptive females) and $75 E 24 C 3^{G / A}$ heterozygotes (presumptive males; Table 2). This sex ratio is slightly female biased, but not different from the 1:1 ratio $\left(\chi^{2}=0.1, P=0.75, \mathrm{DF}=1\right)$. Thus, these previously missing phenotypes are consistent with the observed pattern of female-biased sex ratios in WILD2. We also note that no significant correlation was observed between age at metamorphosis and E24C3 genotype when all 338 metamorphic individuals were considered $(t=1.14$, $P=0.26, \mathrm{DF}=336$ ). Thus, there is no evidence of an
Table 2 Segregation of E24C3 genotypes and sex phenotypes in a subset of the WILD2 cross

\begin{tabular}{lrr}
\hline Sex & $E 24 C 3^{G / G}$ & $E 24 C 3^{G / A}$ \\
\hline Female & 160 & 23 \\
Male & 11 & 117 \\
Early metamorphosing & 79 & 75 \\
\hline
\end{tabular}

Table 3 Segregation of E26C11 genotypes and sex phenotypes in a subset of the WILD2 cross

\begin{tabular}{lcc}
\hline Sex & $E 26 C 11^{A / A}$ & $E 26 C 11^{A / G}$ \\
\hline Female & 24 & 14 \\
Male & 8 & 28
\end{tabular}

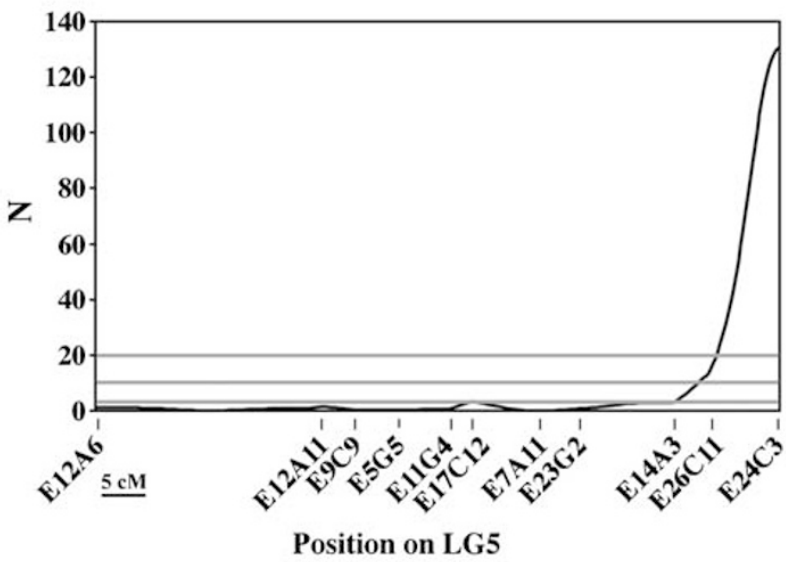

Figure 1 Plot of likelihood ratio statistics (LRS) for association between segregation of sex phenotypes and marker genotypes on LG5 (WILD2). Horizontal lines represent (from bottom to top) linkage group-wide LRS thresholds for suggestive (37th percentile), significant (95th percentile), and highly significant (99.9th percentile) associations (Lander and Kruglyak, 1995) estimated using MapManager QTXb19 (Meer et al., 2004) and 24-74 informative progeny.

effect of sex on metamorphic timing under our rearing conditions.

\section{Association between E24C3 and sex in MEX1}

We extended the previous mapping results to the intraspecific level by testing the hypothesis that E24C3 is linked to the sex-determining factor in the species $A$. mexicanum. To test this hypothesis, 85 individuals from the cross MEX1 were genotyped for two single nucleotide polymorphisms that segregated within the E24C3 marker fragment. Genotypes for E24C3 were strongly associated with the segregation of male and female phenotypes in the MEX1 panel (Figure 2; for $E 24 C 3^{318}$, $\mathrm{LRS}=20.3, P=1 E-5 n=85 ;$ for $E 24 C 3^{79}, \mathrm{LRS}=25.0$, $P<1 E-5, n=85)$. As was the case in the WILD2 mapping family, the pattern of association in the MEX1 cross is consistent with the previously shown ZW sex-determining mechanism of $A$. mexicanum (Humphrey, 1945, 1957; Lindsley et al., 1956; Armstrong, 1984; Figure 2). Using MEX1, the distance between E24C3 and the sexdetermining factor is estimated at approximately 


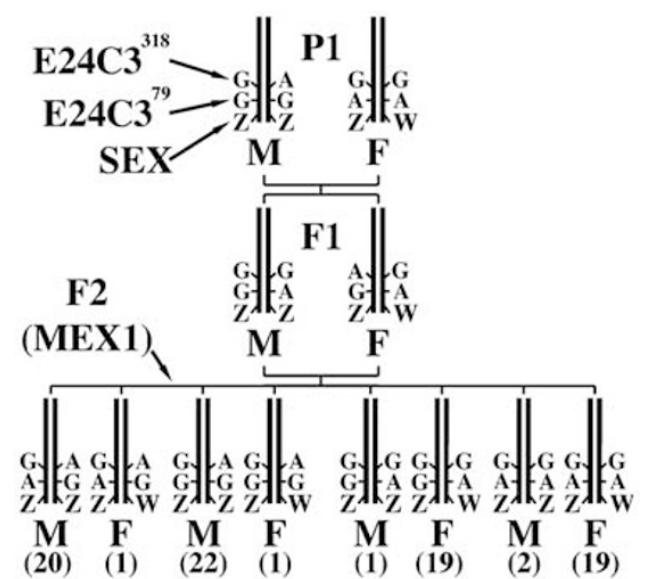

Figure 2 Diagram of the crossing design that was used to generate the MEX 1 cross and segregation of E24C3 marker genotypes and $\mathrm{Z} / \mathrm{W}$ alleles of the ambysex locus in this crossing design. The numbers of individuals that inherited each multilocus genotype are in parentheses. $\mathrm{M}=$ male, $\mathrm{F}=$ female. E24C3 SNP (single nucleotide polymorphism) markers are on the same PCR fragment.

$5.9 \mathrm{cM}$. This is similar to the estimate obtained using the WILD2 panel.

\section{Discussion}

\section{Localization of a major sex-determining factor of}

\section{A. mexicanum}

Localization and inheritance of a single sex-determining factor in A. mexicanum is consistent with results of the earlier genetic studies of sex-determination. The earlier studies firmly established a ZW-type sex-determining mechanism for A. mexicanum (Humphrey, 1945, 1957; Lindsley et al., 1956; Armstrong, 1984), and linkage analyses showed that the sex-determining factor is not linked to a centromere (Lindsley et al., 1956; Armstrong, 1984). The patterns of association between $E 24 C 3$ and sex are consistent with the segregation of a female-specific ' $W$ ' locus, and the terminal location of ambysex on LG5 indicates that it is very distant from the centromere, as all of the larger chromosomes are metacentric in Ambystoma (Callan, 1966). The sex-linked region of LG5 corresponds to human chromosome 2 (Smith and Voss, 2006). We have not yet identified a definitive ortholog for E24C3.

It is curious that ambysex maps to one of the larger linkage groups in the genome. The estimated length of the smallest linkage group of the Ambystoma map $(\mathrm{LG} 14=125.5 \mathrm{cM})$ is considerably smaller than LG5 (292 cM). Before our study, the data were equivocal with regards to the location of the sex-determining locus and whether this locus was associated with dimorphic sex chromosomes. Two cytogenetic studies previously reported subtle heteromorphisms of the smallest chromosome pair that were consistent with ZW segregation (Hauschuka and Brunst, 1965 Cuny and Malacinski, 1985). However, other analyses of tiger salamander (A. mexicanum and A. t. tigrinum) karyotypes do not report sex-specific heteromorphisms (Parmenter, 1919; Dearing, 1934), and Callan (1966) disputed their existence. Our results support the idea that the sex- determining locus is on one of the larger chromosome pairs. By logical extension, this suggests that the $\mathrm{Z}$ and $\mathrm{W}$ chromosomes of $A$. mexicanum are not morphologically differentiated to any appreciable degree.

\section{Recombination rates in the ambysex-linked region imply a recent origin for ambysex}

Previously published linkage analyses were based on recombination that occurred in the testes of male (presumably ZZ) F1 hybrids between A. mexicanum and A.t. tigrinum (Voss, 1995; Smith et al., 2005). Estimates of linkage distance in WILD2 are based on female (ZW) recombination, and estimates of linkage distance in MEX1 are based on the recombination in both sexes. Divergence of tiger salamander $\mathrm{Z}$ and $\mathrm{W}$ chromosomes should tend to reduce recombinational distances in female meiosis relative to male meiosis. The recombinational distance between E24C3 and a Mendelian ambysex locus in WILD2 is similar to the distance between E24C3 and ambysex in the male and female F1s that founded MEX1 (Table 2, Figure 2). Moreover, the estimated ZW recombinational distance between E24C3 and E26C11 was $30.2 \mathrm{cM}$ in WILD2, higher than the estimated $\mathrm{ZZ}$ recombinational distance $(13.6 \mathrm{cM})$ for these same loci in AxTg (Smith et al., 2005). In the few other cases where recombination frequencies have been characterized for young ( $\sim 10$ million years old) sex chromosomes (for example, medaka: Kondo et al., 2004; stickleback: Peichel et al., 2004; and papaya: Liu et al., 2004; Ma et al., 2004), the frequency of recombination in the $30-100 \mathrm{cM}$ adjacent to the sex-determining factor is substantially reduced within the heterogametic sex, relative to the homogametic sex. Given the lack of evidence for differences in recombination frequency in this study, the recent radiation of the tiger salamander species complex (Shaffer and McKnight 1996) and the lack of convincing cytogenetic evidence for structurally differentiated sex chromosomes in the tiger salamander lineage, it stands for the reason that the ambysex locus arose quite recently, perhaps within the last 5-10 million years.

\section{Female bias in WILD2}

Although the evidence is strong for the presence of a major sex-determining locus in WILD2, the observation of slight, but consistent, female bias indicates that additional factors may have also influenced segregation of sex in this mapping family. It is interesting to note that sex bias in WILD2 is in the opposite direction of biases that might be expected to arise from hybrid incompatibilities that depend on the hemizygous inheritance of a differentiated Z chromosome (Haldane's rule; Presgraves and Orr, 1998; Turelli and Orr, 2000). It is also notable that in WILD2 and MEX1, the number of females with presumptively recombinant genotypes $\left(n=23, E 24 C 3^{\mathrm{G} / A}\right.$ females in WILD2) is greater than the number of presumptively recombinant males $\left(n=11, E 24 C 3^{\mathrm{G} / \mathrm{G}}\right.$ males in WILD2). The greater number of females might reflect the presence of additional genetic factors that cause $\mathrm{ZZ}$ individuals to develop as females, or an increased mortality of male recombinants during prehatching stages. Identification of markers that are more tightly linked to the sex-determining locus, or the sex-determining locus itself, should ultimately permit 
recombinant individuals to be differentiated from potentially sex-reversed individuals.

It is also possible, though perhaps less likely, that female-biased sex ratios were generated as a result of environmental conditions under which WILD2 offspring were reared. Although all WILD2 individuals experienced very similar environmental conditions, it is formally possible that these conditions increased the probability that individuals developed as females, irrespective of genotype. Temperature is known to affect the sex ratio in some salamanders (reviewed by Wallace et al., 1999), but only at extreme levels that are not encountered during normal laboratory culture. Perhaps more importantly, the only study to test for environmental effects on sex ratios in Ambystoma found no deviation from a $1: 1$ sex ratio in $A$. tigrinum or A. maculatum reared at 13 or $22^{\circ} \mathrm{C}$ (Gilbert, 1936), which encompasses the range of temperature variation within this study. Thus, it seems unlikely that the observed slight female bias was caused by rearing temperature in WILD2 crosses. With validated markers for sex, it is now possible to systematically test for environmental effects on sex determination in A. mexicanum and possibly other members of the tiger salamander species complex.

\section{Sex and the biology of ambystomatid salamanders}

Results from WILD2 indicate that the genetic sexdetermining mechanism of $A$. mexicanum functions within the genomes of $\mathrm{F} 1$ hybrids between $A$. mexicanum and A. t. tigrinum, and their backcross offspring. This suggests that the genetic sex determining mechanism of A. mexicanum is likely to be conserved in many closely related species that comprise the tiger salamander species complex. Tiger salamanders are important models for studying development (Monaghan et al., 2007; Zhang et al., 2007), ecology (Trenham and Shaffer, 2005; Fitzpatrick and Shaffer, 2004; Brunner et al., 2005) and evolution (Voss and Smith, 2005; Robertson et al., 2006; Weisrock et al., 2006). Thus, the sex markers described in this study will open many new avenues of research and will allow better management of laboratory populations. For example, it should be straightforward to develop orthologous markers for other closely related tiger salamanders and determine whether sex-determining mechanisms are conserved or different. Studies of more distantly related taxa are also needed (Ogata et al., 2003; Ezaz et al., 2006) to fully characterize the evolution and diversity of sex-determining mechanisms in amphibians.

\section{Acknowledgements}

This study was supported by Grants R24-RR016344 and P20-RR016741 from the National Center for Research Resources (NCRR), a component of the National Institutes of Health $(\mathrm{NIH})$. Its contents are solely the responsibility of the authors and do not necessarily represent the official views of NCRR or NIH. The National Science Foundation provided support through IBN-0242833. The Spinal Cord and Brain Injury Research Center at the United Kingdom and the NSF-supported Ambystoma Genetic Stock Center (DBI-0443496) provided resources and facilities. We also thank K Peichel for providing a critical review of the manuscript before submission.

\section{References}

Armstrong JB (1984). Genetic Mapping in the Mexican axolotl, Ambystoma mexicanum. Can J Genet Cytol 26: 1-6.

Asashima M, Malacinski GM, Smith SC (1989). Surgical manipulation of embryos. In: Armstrong JB, Malacinski GM (eds). Developmental Biology of the Axolotl. Oxford University Press: New York. pp 252-263.

Baroiller JF, Guigen Y, Fostier A (1999). Endocrine and environmental aspects of sex differentiation in fish. Cell Mol Life Sci 55: 910-931.

Brunner JL, Richards K, Collins JP (2005). Dose and host characteristics influence virulence of ranavirus infections. Oecologia 144: 399-406.

Brunst VV, Hauschka TS (1963). Length measurements of the diploid karyotype of the Mexican axolotl (Siredon mexicanum) with reference to a possible sex difference. Proc XVIth int Congr Zool, Wash 2: 274.

Callan HG (1966). Chromosomes and nucleoli of the axolotl, Ambystoma mexicanum. J Cell Sci 1: 85-108.

Chen X, Levine L, Kwok P-Y (1999). Fluorescence polarization in homogenous nucleic acid analysis. Genome Res 9: 492-498.

Collenot A, Durand D, Lauther M, Dorazi R, Lacroix JC, Dournon C (1994). Spontaneous sex reversal in Pleurodeles waltl (urodele amphibia): analysis of its inheritance. Genet Res 64: 43-50.

Cuny R, Malacinski GM (1985). Banding differences between tiger salamander and axolotl chromosomes. Can J Genet Cytol 27: 510-514.

Dearing Jr WH (1934). The maternal continuity an individuality of the somatic chromosomes of Ambystoma tigrinum, with special reference to the nucleolus as a chromosomal component. J Morph 56: 157-179.

Delvin RH, Nagahama Y (2002). Sex determination and sex differentiation in fish: an overview of genetic, physiological, and environmental influences. Aquaculture 208: 191-364.

Ewert MA, Nelson CE (1991). Sex determination in turtles: diverse patterns and some possible adaptive values. Copeia $\mathbf{1}$ 50-69.

Ezaz T, Stiglec R, Veyrunes F, Graves JAM (2006). Relationships between vertebrate $\mathrm{ZW}$ and $\mathrm{XY}$ sex chromosome systems. Curr Biol 16: R736-R743.

Fitzpatrick BM, Shaffer HB (2004). Environment-dependent admixture dynamics in a tiger salamander hybrid zone. Evolution 58: 1282-1293.

Gardiner AF, Jack WE (2002). Acyclic and dideoxy terminator preferences denote divergent sugar by archaeon detection. BioTechniques 31: 560-570.

Gilbert WM (1936). Amphisexuality and sex differentiation in Ambystoma. Unpublished Thesis, State University of Iowa.

Hauschuka TS, Brunst VV (1965). Sexual dimorphism in the nucleolar autosome of the axolotl (Sirenodon mexicanum). Hereditas 52: 345-356.

Hayes TB (1998). Sex determination and primary sex differentiation in amphibians: genetic and developmental mechanisms. I Exp Zoo 281: 373-399.

Hillis DM, Green DM (1990). Evolutionary changes of heterogametic sex in the phylogenetic history of amphibians. J Evol Biol 3: 49-64.

Hsu TM, Chen X, Duan S, Miller RD, Kwok P-Y (2001). Universal SNP genotyping assay with fluorescence polarization detection. Nucleic Acids Res 30: 605-613.

Humphrey RR (1929). Studies on sex reversal in Ambystoma: bisexuality and sex reversal in larval males uninfluenced by ovarian hormones. Anat Rec 42: 119-155.

Humphrey RR (1945). Sex determination in the Ambystomatid salamanders: a study of the progeny of females experimentally converted into males. Am J Anat 76: 33-66.

Humphrey RR (1957). Male homogamety in the Mexican axolotl: a study of the progeny obtained when germ cells 
of a genetic male are incorporated into the developing ovary. J Exp Zoo 134: 91-101.

Just W, Rau W, Vogel W, Akhverdian M, Fredga K, Graves JAM et al. (1995). Absence of SRY in species of the vole Ellobius. Nat Genet 11: 117-118.

Kondo M, Nanda I, Hornung U, Schmid M, Schartl M (2004). Evolutionary origin of the medaka Y chromosome. Curr Biol 14: 1664-1669.

Lander E, Kruglyak L (1995). Genetic dissection of complex traits: guidelines for interpreting and reporting linkage results. Nat Genet 11: 241-247.

Lindsley DL, Fankhauser G, Humphrey RR (1956). Mapping centromeres in the axolotl. Genetics 41: 58-64.

Liu ZY, Moore PH, Ma H, Ackerman CM, Ragiba M, Yu Q et al. (2004). A primitive $Y$ chromosome in papaya marks incipient sex chromosome evolution. Nature 427: 348-352.

Ma H, Moore PH, Liu Z, Kim MS, Yu Q, Fitch MMM et al. (2004). High-density linkage mapping revealed suppression of recombination at the sex determination locus in papaya. Genetics 166: 419-436.

Mank JE, Promislow DEL, Avise JC (2006). Evolution of alternative sex-determining mechanisms in teleost fishes. Biol J Linn Soc Lond 87: 83-93.

Meer JM, Cudmore Jr RH, Manly KF (2004). MapManager QTX. http:/ / ww.mapmanager.org/mmQTX.html.

Monaghan JR, Walker JA, Beachy CK, Voss SR (2007). Microarray analysis of early gene expression during natural spinal cord regeneration in the salamander Ambystoma mexicanum. J Neurochem 101: 27-40.

Nanda I, Schmid M (2002). Conservation of avian Z chromosomes as revealed by comparative mapping of the Z-linked aldolase B gene. Cytogenet Genome Res 96: 176-178.

Nanda I, Zend-Ajusch E, Shan Z, Grutzner F, Schartl M, Burt DW et al. (2000). Conserved synteny between the chicken $\mathrm{Z}$ sex chromosome and human chromosome 9 includes the male regulatory gene DMRT1: a comparative (re)view on avian sex determination. Cytogenet Genome Res 89: $67-78$.

Ogata M, Ohtani H, Igarashi T, Hasegawa Y, Ichikawa Y, Miura I (2003). Change of the heterogametic sex from male to female in the frog. Genetics 164: 613-620.

Olmo E (1990). Cytogenetics of Reptiles and Amphibians. Birkhauser Verlag: Basel, Switzerland.

Page RB, Voss SR, Samuels AK, Smith JJ, Putta S, Beachy CK (2008). Effect of thyroid hormone concentration on the transcriptional response underlying induced metamorphosis in the Mexican axolotl (Ambystoma). BMC Genomics 9: 78

Parmenter CL (1919). Chromosome number and pairs in the somatic mitoses of Ambystoma tigrinum. J Morph 33: 169-242.

Pask AJ, Graves JAM (1999). Sex chromosomes and sexdetermining genes: insights from marsupials and monotremes. Cell Mol Life Sci 55: 864-875.

Peichel CL, Ross JA, Matson CK, Dickson M, Grimwood J, Schmutz J et al. (2004). The master sex-determination locus in threespine sticklebacks is on a nascent $\mathrm{Y}$ chromosome. Curr Biol 14: 1416-1424.

Presgraves DC, Orr HA (1998). Haldane's rule in taxa lacking a hemizygous X. Science 282: 952-954.

Pieau C, Dorizzi M, Richard-Mercier N (1999). Temperature dependant sex determination and gonadal differentiation in reptiles. Cell Mol Life Sci 55: 887-900.
Richards CM, Nace GW (1978). Cytogenetic and hormonal sex reversal used in tests of the XX-XY hypothesis of sex determination in Rana pipiens. Growth 42: 319-331.

Robertson AV, Ramsden C, Niedzwiecki J, Fu ZJ, Bogart JP (2006). An unexpected recent ancestor of unisexual Ambystoma. Mol Ecol 15: 3339-3351.

Schmid M, Nanda I, Steinlein C, Kausch K, Epplen JT, Haaf T (1991). Sex determining mechanisms and sex chromosomes in amphibia. In: Green DM, Sessions SK (eds). Amphibian Cytogenetics and Evolution. Academic Press: New York. pp 393-430.

Sessions SK (1982). Cytogenetics of diploid and triploid salamanders of the Ambystoma jeffersonianum complex. Chromosoma 77: 599-621.

Shaffer HB (1984). Evolution in a paedomorphic lineage. 1. An electrophoretic analysis of the Mexican ambystomatid salamanders. Evolution 38: 1194-1206.

Shaffer HB, McKnight ML (1996). The polytypic species revisited: Genetic differentiation and molecular phylogenetics of the tiger salamander, Ambystoma tigrinum (Amphibia: Caudata) complex. Evolution 50: 417-433.

Shine R (1999). Why is sex determined by nest temperature in so many reptiles? Trends Ecol Evol 14: 186-189.

Sinclair A, Berta HP, Palmer MS, Hawknis JR, Griffiths BL, Smith MJ et al. (1990). A gene from the human sexdetermining region encodes a protein with homology to a conserved DNA-binding motif. Nature 346: 240-244.

Smith JJ, Voss SR (2006). Gene order data from a model amphibian (Ambystoma): new perspectives on vertebrate genome structure and evolution. BMC Genomics 7: 219.

Smith JJ, Kump DK, Walker JA, Parichy DM, Voss SR (2005). A comprehensive expressed sequence tag linkage map for tiger salamander and Mexican axolotl: enabling gene mapping and comparative genomics in Ambystoma. Genetics 171: 1161-1171.

Sokal FJ, Rohlf RR (1995). Biometry: the Principles and Practice of Statistics in Biological Research, 3rd edn. WH Freeman and Company: New York.

Soullier S, Hanni C, Catzeflis F, Berta P, Laudet V (1998). Male sex. determination in the spiny rat Tokudaia osimensis (Rodentia: Muridae) is not Sry dependent. Mamm Genome 9: 590-592.

Trenham PC, Shaffer HB (2005). Amphibian upland habitat use and its consequences for population viability. Ecol Appl 15: $1158-1168$.

Turelli M, Orr HA (2000). Dominance, epistasis and the genetics of postzygotic isolation. Genetics 154: 1663-1679.

Voss SR (1995). Genetic basis of paedomorphosis in the axolotl Ambystoma mexicanum: a test of the single gene hypothesis. $J$ Hered 86: 441-447.

Voss SR, Smith JJ (2005). Evolution of salamander life cycles: A major effect QTL contributes to discreet and continuous variation for metamorphic timing. Genetics 170: 275-281.

Wallace HG, Badawy MI, Wallace BM (1999). Amphibian sex determination and sex reversal. Cell Mol Life Sci 55: 901-909.

Weisrock DW, Shaffer HB, Storz BL, Storz SR, Voss SR (2006). Multiple nuclear gene sequences identify phylogenetic species boundaries in the rapidly radiating clade of Mexican ambystomatid salamanders. Mol Ecol 15: 2489-2503.

Zhang C, Pietras KM, Sferrazza GF, Jia P, Athauda G, Rveda-deleon $\mathrm{E}$ et al. (2007). Molecular and immunohistochemical analyses of cardiac troponin $\mathrm{T}$ during cardiac development in the Mexican axolotl, Ambystoma mexicanum. I Cell Biochem 100: 1-15.

Supplementary Information accompanies the paper on Heredity website (http://www.nature.com/hdy) 